\title{
Ensino da Ciência da Computação na Educação Básica: $O$ que alguns países de fala espanhola estão fazendo, e o que podemos fazer no Brasil?
}

\author{
André Souza Lemos ${ }^{1}$, Daniel Carlos de Freitas ${ }^{2}$ \\ Instituto Federal de Educação, Ciência e Tecnologia do Triângulo Mineiro (IFTM) \\ Caixa Postal 38.411-104 - Uberlândia - MG - Brazil \\ andre.lemos@iftm.edu.br, freitas.danielcarlos@gmail.com
}

\begin{abstract}
Resumo. O presente trabalho pretende apresentar a análise dos avanços e desafios enfrentados por educadores de países de fala espanhola, quanto ao ensino de conteúdos da Ciência da Computação a alunos da Educação Básica. Com essa finalidade, foram analisados materiais didáticos, relatórios e referenciais, elaborados coletivamente entre professores, pesquisadores elou representantes de empresas privadas, os quais para além de estabelecerem a relevância da presença do conhecimento computacional na sociedade contemporânea, trazem métodos e conteúdo que podem ser utilizados ao se introduzir o ensino da Ciência da Computação na Educação Básica.
\end{abstract}

\begin{abstract}
The present work intends to present the analysis of the advances and challenges faced by educators of Spanish speaking countries, regarding the development of educational projects aiming at the teaching of Computer Science subjects to K-12 students. To this end, didactic materials, reports and references that were elaborated as a collective effort of teachers, researchers and/or members of private companies were analyzed, which in addition to establishing the relevance of the presence of computational knowledge in contemporary society, bring methods and contents that could be used when introducing the teaching of Computer Science in Basic Education.
\end{abstract}

\section{Introdução}

Desde sua criação em 1997 na Universidade de Brasília, é possível observar que o curso de Licenciatura em Computação vivenciou distintos momentos, do que dá testemunho a variação do número dos cursos ofertados, de acordo com a literatura atual e os dados apontados em censos realizados por órgãos reguladores. No final da década de 1990, houve o surgimento do supracitado curso em universidades públicas estaduais, logo de um prévio período germinal. Em meados dos anos 2000 entram em cena as Instituições de Ensino Superior - IES privadas, porém sendo a oferta desse curso nessas instituições

\footnotetext{
${ }^{1}$ Possui bacharelado em Ciência da Computação pela Universidade Federal do Rio Grande do Sul (1987), mestrado em Ciência da Computação pela mesma universidade (1990) e doutorado em Comunicação e Semiótica: Tecnologias da Informação pela Pontifícia Universidade Católica de São Paulo (2001). Atualmente é professor no curso de Licenciatura em Computação do Instituto Federal do Triângulo Mineiro - Campus Uberlândia Centro.

2 Discente no curso de Licenciatura em Computação no Instituto Federal de Educação Ciência e Tecnologia do Triângulo Mineiro IFTM - Campus Uberlândia Centro, bolsista no Programa Institucional de Bolsa de Iniciação à Docência PIBID, experiência na área de Ciência da Computação, com ênfase em Metodologia e Técnicas da Computação.
} 
vítima de um rápido declínio. A partir da década de 2010 o curso vivencia um novo cenário com o surgimento dos Institutos Federais, além de programas de incentivo e melhoramento para a formação docente, como o Programa Institucional de Bolsa de Iniciação à Docência - PIBID e o Prodocência (LEMOS 2013, p.03). Sobre esse novo contexto, acreditamos que embora não vivenciemos um crescimento tão vertiginoso quanto o experimentado no início dos anos 2000, é possível que estejamos passando por uma fase de maturidade, em que ações conjuntas de já licenciados em computação e organizações relacionadas ao tema, permitam que se alcancem resultados relevantes. A homologação das diretrizes curriculares para os cursos da área da Computação, ocorrida no final do ano de 2016, bem como a recente publicação pela Sociedade Brasileira de Computação do documento intitulado "Referenciais de Formação em Computação: Educação Básica" (SBC, 2017), além da elaboração dos referenciais de formação dos cursos de Licenciatura em Computação por essa mesma sociedade, são sinais de que esse período de maturidade pode estar se aproximando.

Também testemunhamos recentemente em território nacional, uma relativa mudança de percepção quanto ao ensino da Ciência da Computação para crianças e adolescentes. De acordo com o publicado pela jornalista Cris Olivette no dia 09 de outubro de 20016, na versão digital do Jornal O Estadão, no Brasil "Cresce o número de escolas que ensinam linguagem de programação para crianças" (OLIVETTE, 2016), afirmando ainda que o "Ensino de Linguagem de Programação para crianças não para de atrair empreendedores, tanto para ser franqueado quanto para criar uma marca" (OLIVETTE, 2016). Junto a essas informações é apresentada uma lista de centros de formação complementar, direcionados ao ensino da Ciência de Computação. Ditas instituições para além de ofertarem cursos na forma de módulos em suas instalações, também realizam parcerias com escolas de ensino regular, levando até elas os produtos dos quais dispõem.

A necessidade de conciliar o ensino da Ciência da Computação com a Educação Básica percebeu-se uma necessidade não apenas do Brasil, mas objetivo perseguido também por países desenvolvidos, sendo nesse texto apresentada uma breve análise de algumas ações colocadas em prática em países de fala espanhola, consultando documentos e textos produzidos originalmente neles.

Ponderamos ser de relevância poder analisar alguns exemplos e casos da abordagem dada ao ensino da Ciência da Computação no nível da Educação Básica em países de fala espanhola, para que as possamos cotejar com as referências que se tem no Brasil nesse sentido, de modo que nos permita apresentar para a discussão o tema em questão, sem pressupor que se trata de uma necessidade caracterizada apenas pela influência que exercem os países que estão na vanguarda do desenvolvimento tecnológico e científico, e sim uma característica transversal da sociedade global do século XXI.

\section{México}

A Universidade Nacional Autônoma do México - UNAM é uma instituição pública, reconhecidamente uma das principais universidades no contexto mundial, e considerada o principal centro de pesquisa acadêmica do México, tendo entre seus egressos até a presente data três prêmio Nobel: Octavio Paz - Prêmio Nobel de Literatura; Alfonso García Robles - Prêmio Nobel da Paz; e Mário José Molina - Prêmio Nobel de 
VI Congresso Brasileiro de Informática na Educação (CBIE 2017)

Anais dos Workshops do VI Congresso Brasileiro de Informática na Educação (WCBIE 2017)

Química. Entre suas propostas no âmbito do ensino, desenvolvem um projeto que objetiva a oferta de aulas no campo da Educação Básica, especificamente no ensino médio. Esse trabalho por eles desenvolvido se intitula "Programa de Conhecimentos Fundamentais para o Ensino Médio" [tradução nossa]. Valendo-se dos bons recursos dos quais dispõe, incluindo um grupo qualificado de professores e pesquisadores, além de uma editora própria, para atender a demanda de material didático específico que pudessem ser utilizados pelos professores nas aulas ministradas na esfera do ensino médio, a UNAM então se propõe a desenvolver seu próprio material didático. Entre as disciplinas que são abordadas nesse contexto educacional do ensino médio, está presente o ensino da Ciência da Computação. O livro referenciado abaixo é produzido especificamente para o ensino da Ciência da Computação ao longo dos três anos que compõem o ensino médio.

O livro se intitula "Conhecimentos Fundamentais da Computação", sendo editado pela própria universidade e elaborado por quatro autores com conhecimentos específicos no âmbito da Ciência da Computação. Percebe-se que sua elaboração, se dá por meio de uma instituição consolidada no campo do ensino e da pesquisa, com a ação direta de pessoas qualificadas para esse fim.

No livro anteriormente citado, produzido pela Universidade Autônoma do México, os conteúdos da Ciência da Computação são apresentados em forma de módulos, propondo ainda atividades didáticas que objetivam a assimilação e fixação dos temas abordados. Na imagem abaixo apresentamos os conceitos que o livro aborda em cada uma de suas sessões, apontando ainda os subtópicos correspondentes:

\footnotetext{
${ }^{3}$ Programa Conocimientos Fundamentales para la Enseñanza Media Superior. (UNAM, 2009, p.4).
} 
VI Congresso Brasileiro de Informática na Educação (CBIE 2017)

Anais dos Workshops do VI Congresso Brasileiro de Informática na Educação (WCBIE 2017)

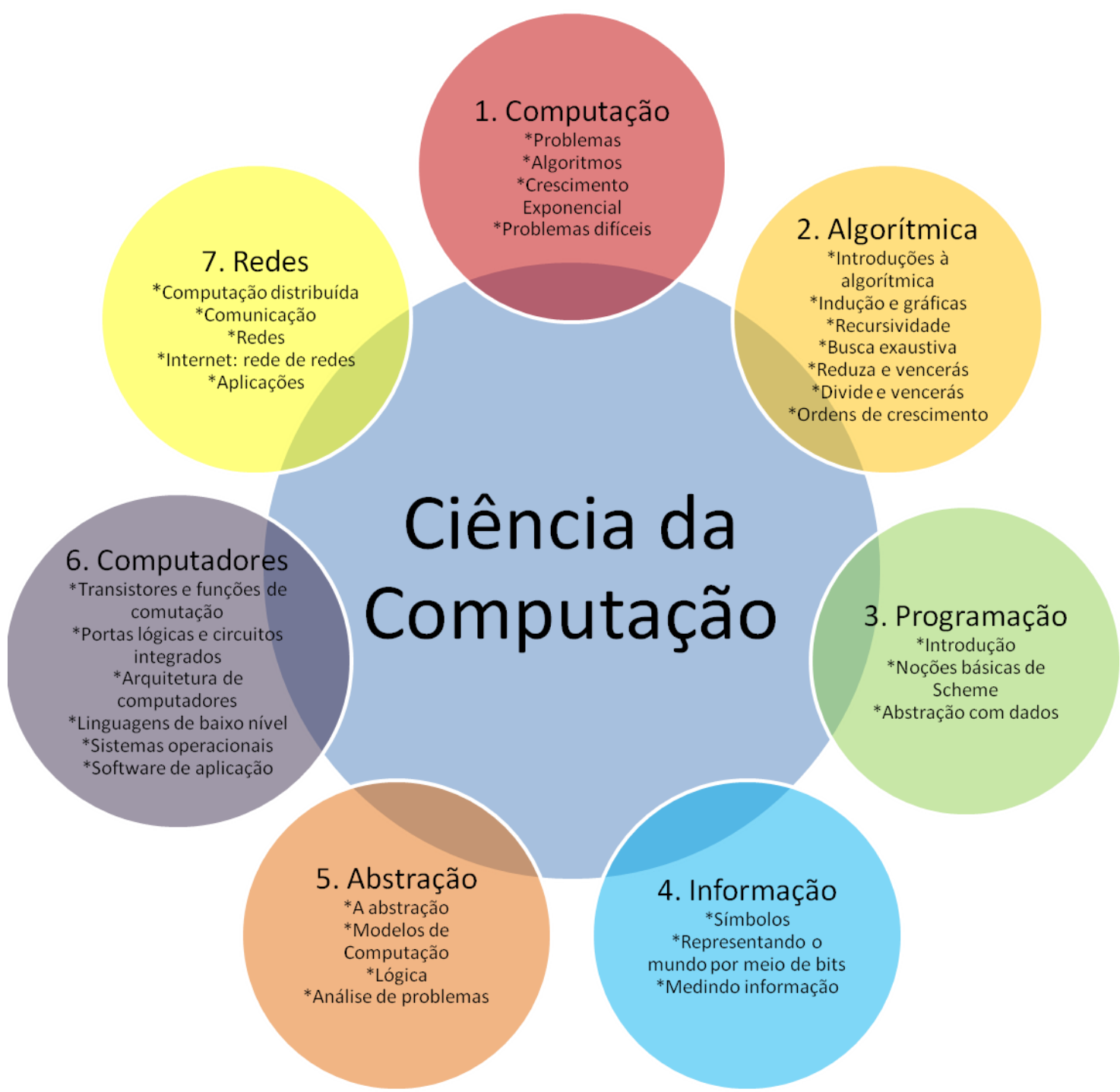

Fig. 1 "Módulos de Estudo - Livro Conhecimentos Fundamentais da Computação"

Quando os autores se dispõem a apresentar a computação, não mencionam a palavra computador. Uma das maiores dificuldades de se tratar os conceitos da computação na Educação Básica, é justamente a indefinição de términos relativos à computação, aceitos no senso comum, sendo assim, é possível imaginar que o uso do termo computador prematuramente em um ambiente educacional com alunos da Educação Básica, limitasse o entendimento do conceito computação.

Os conceitos da Computação são apresentados buscando-se a contextualização dos termos com a própria vida. Inicialmente não se fala de computação, se fala de pensamento, inteligência, raciocínio e lógica. É apresentado o ser humano, efêmero, vulnerável e frágil, quando diante das peripécias e desafios que o mundo lhe impõe. Nesse contexto, resta ao homem lançar mão do seu melhor recurso: o pensamento.

Essa forma de abordar os conceitos da Ciência da Computação está presente ao longo de todo o livro, seja por meio de notas de rodapé ou biografias resumidas de personagens relevantes a cada contexto abordado, além da proposta de atividades 
VI Congresso Brasileiro de Informática na Educação (CBIE 2017)

Anais dos Workshops do VI Congresso Brasileiro de Informática na Educação (WCBIE 2017)

práticas para fixação do conteúdo trabalhado. No primeiro capítulo do livro, quando o aluno será apresentado à computação, ele já terá a consciência que:

As criaturas que habitam o mundo da computação são os dados. Estes são manipulados para resolver problemas mediante algoritmos. De todos os problemas, alguns se podem resolver eficientemente, se acredita que outros não (embora não se saiba ao certo), e a grande maioria ou não se podem resolver em um tempo razoável, ou simplesmente não se podem resolver, e ponto. ${ }^{4}$ [tradução nossa] (UNAM, 2009, p.21).

Observa-se claramente que não há nos autores apenas a intenção de mencionar a usabilidade de um software computacional, essa ideia nem mesmo é cogitada por eles em um primeiro momento. Existe sim de forma clara, a conceitualização da abstração do conhecimento computacional. É o ensino específico da Ciência da Computação, em vez de apenas o uso do computador.

\section{Espanha}

Para analisar as ações desenvolvidas na Espanha no tocante ao ensino da Ciência da Computação na Educação Básica, iniciamos com a consulta ao documento "Educação em Ciências da Computação na Espanha 2015": Trata-se de um relatório produto de uma pesquisa produzida por meio de uma parceria entre as empresas Google e Everis, a Fundação Espanhola Para a Ciência e Tecnologia, e o Ministério de Economia e Competitividade do Governo da Espanha, tendo como contexto os países da União Europeia. Nas palavras dos próprios autores do referido documento:

O presente informe foi elaborado por Google junto à Fundação Espanhola para a Ciência e a Tecnologia (FECYT) e Everis, e tem como objetivo analisar a situação atual do ensino de meninas e meninas entre 6 e 16 anos. Este informe propõe uma série de recomendações para a introdução, expansão e melhora do ensinamento desta matéria no curto e longo prazo. ${ }^{5}$ (Tradução nossa).

Por meio da leitura do documento citado, é possível ter um panorama do ensino da Ciência da Computação na Educação Básica na Espanha, e traçar um paralelo entre este país, e as demais nações da União Europeia. Para isso, os autores do relatório realizaram "no mês de outubro de 2015 um total de 2.324 pesquisas: 1.210 destinadas aos pais e mães, 609 destinadas a pais e mães com filhos e filhas com idades entre $6 \mathrm{e}$ 11 anos e 505 destinadas aos pais e mães de filhos e filhas com idades entre 12 e 16

\footnotetext{
${ }^{4}$ Las criaturas que habitan el mundo de la computación son los datos. Éstos se manipulan para resolver problemas mediante algoritmos. De todos los problemas, algunos se pueden resolver eficientemente, otros se cree que no - aunque no se sabe a ciencia cierta - , y la gran mayoría o no se pueden resolver en un tiempo razonable, o simplemente no se pueden resolver, punto. (UNAM, 2009, p.21).

${ }^{5}$ El presente informe ha sido elaborado por Google junto a la Fundación Española para la Ciencia y la Tecnología (FECYT) y Everis y tiene como objetivo analizar la situación actual de la enseñanza de Ciencias de la Computación (CC) en España para niños y niñas de entre 6 y 16 años. Este informe propone una serie de recomendaciones para la introducción, expansión y mejora de la enseñanza de esta materia en el corto y medio plazo. (Google; España; FECYT; Everis. 2006. "Educación en Ciencias de la Computación en España 2015” p. 02).
} 
anos " " [tradução nossa] (Gobierno de España, 2015, p.29), analisando a percepção dos entrevistados nos seguintes oito temas: a) O conhecimento existente da sociedade espanhola sobre a Ciência da Computação; b) Estado atual do ensino da ciência da computação na Espanha; c) A percepção das famílias quanto a importância da Ciência da Computação; d) O interesse dos alunos; e) Brecha de gênero no estudo da Ciência da Computação; f) Apoio das famílias; g) $\mathrm{O}$ uso de dispositivos tecnológicos e $\mathrm{h}$ ) Preparação do agremiado docente para o ensino da Ciência da Computação.

Ao longo do relatório, os dados apontam para a necessidade presente na sociedade quanto ao entendimento da Ciência da Computação, apresentando nas considerações finais algumas estratégias e orientações para o desenvolvimento de atividades que permitam a inserção desse campo do conhecimento em grades curriculares da Educação Básica.

Quando se pretende propor a inclusão do ensino da Ciência da Computação na Educação Básica, para além de formar licenciados em computação, necessariamente é preciso também pensar em metodologias de ensino, relação entre conteúdo de estudo e faixa etária de alunos, carga horária adequada para abordagem e assimilação dos conceitos, métodos de avaliação, entre outras particularidades próprias da prática docente. Levando isso em consideração, acreditamos ser relevante para a fundamentação de discussões nesse âmbito, um documento elaborado em parceria entre governo e empresas privadas, conforme esse que aqui consideramos. A possibilidade da existência de interesses convergentes entre espaços educacionais e empresas privadas, no que diz respeito ao desenvolvimento do conhecimento computacional na sociedade contemporânea, pode ser fator decisivo.

\section{Costa Rica}

De acordo com um documento de pesquisa produzido por Microsoft Latinoamérica, elaborado nos meses de março e abril de 2016, no qual entre autoridades e representantes acadêmicos de países da América Latina se apresenta um panorama do ensino da Ciência da Computação na região, a Costa Rica foi o primeiro país entre os analisados em lançar um programa nacional de associação entre as Tecnologias Digitais de Informação e Comunicação e o processo de ensino e aprendizagem, a meados dos anos 1980 (Microsoft Latinoamérica, 2016). Denominado Programa Nacional de Informática Educacional, é desenvolvido em conjunto pelo Ministério da Educação Pública e a Fundação Omar Dengo. A partir do material consultado, pôde-se perceber que embora em um primeiro momento a proposta dessa iniciativa fosse o uso do computador como ferramenta auxiliar na prática de ensino, desde o ano 2010 as ações se direcionaram para também considerá-lo como objeto de estudo no ambiente escolar.

Para lograr de maneira satisfatória a mudança de direção:

Atualmente, a Fundação Omar Dengo, responsável pelo Programa Nacional de Informática Educacional, está propondo modificar o currículo desses cursos [de informática] para incluir conteúdos próprios da Ciência da Computação, como pensamento

\footnotetext{
6 En el mes de octubre, se llevaron a cabo 2.324 encuestas: 1.210 destinadas a padres y madres, 609 destinadas a padres y madres con hijos e hijas de edades comprendidas entre 6-11 años y 505 destinadas a padres y madres con hijos e hijas de entre 12-16 años. (Gobierno Gobierno de España, 2015, p.29).
} 
VI Congresso Brasileiro de Informática na Educação (CBIE 2017)

Anais dos Workshops do VI Congresso Brasileiro de Informática na Educação (WCBIE 2017)

computacional, robótica e makers. (Tradução Nossa, Microsoft Latinoamérica, 2016, p. 18) ${ }^{7}$.

Nesse contexto, a Fundação Omar Dengo apresentou em meados de 2016 os Referenciais de Desempenho de Estudantes no Aprendizado das Tecnologias Digitais, nos quais se:

[...] estabelece o que o sistema educacional da Costa Rica espera que os estudantes saibam e sejam capazes de fazer com as tecnologias digitais, como resultado da oferta educacional. (Tradução Nossa, Fundación Omar Dengo, 2016, p.26). ${ }^{8}$

A partir desse documento, em sala de aula, os professores poderão avaliar os alunos por seus conhecimentos diretamente relacionados à Ciência da Computação, enquanto anteriormente a ele, a avaliação se dava apenas sobre o conteúdo que estivesse sendo abordado com o uso de ferramentas vinculadas à Computação.

Embora seja fato que na Costa Rica exista um olhar direcionado para o ensino da Ciência da Computação na Educação Básica, não nos foi possível encontrar nos materiais consultados nenhuma proposta concreta quanto ao profissional docente que estará incumbido de abordar tal conteúdo em sala de aula.

Semelhante ao observado na Espanha, em que a articulação entre órgãos públicos e entidades privadas produz parcerias interessantes, no sentido de fomentar o ensino da Ciência da Computação na Educação Básica, há também na Costa Rica essa prática.

\section{Chile}

As primeiras ações do governo chileno direcionadas na vinculação entre Computação e Educação, se deram no início dos anos 1990 por meio do Programa ENLACES, vinculado ao Ministério da Educação.

[...] nasce em 1992 com a finalidade de contribuir para o melhoramento da qualidade da educação por meio da informática educativa e do desenvolvimento de uma cultura digital. Trabalha com todas as escolas subsidiadas do Chile, entregando estratégias de ensino com o uso da tecnologia, capacitando professores, oferecendo oficinas para os estudantes e disponibilizando recursos educacionais digitais e infraestrutura. (Tradução Nossa, ENLACES, 2016). ${ }^{9}$

Novamente se observa que as ações iniciais nais quais se pretende a associação da Computação com a Educação Básica, geralmente se dava por meio de propostas que

\footnotetext{
${ }^{7}$ Actualmente, la Fundación Omar Dengo, responsable del PRONIE, está proponiendo modificar el currículum de este curso [de informática] para incluir contenidos propios de las ciencias de la computación, pensamiento computacional, robótica y makers. (Microsoft Latinoamérica, 2016, p.18).

${ }^{8}[\ldots]$ establecen lo que el sistema educativo costarricense espera que los estudiantes sepan y estén en capacidad de hacer con las tecnologías digitales, como resultado de su oferta educativa. (Fundación Omar Dengo, 2016, p.26).

${ }^{9}$ Enlaces, Centro de Educación y Tecnología del Ministerio de Educación, nace en 1992 con el fin de contribuir al mejoramiento de la calidad de la educación mediante la informática educativa y el desarrollo de una cultura digital. Trabaja con todos los colegios subvencionados de Chile, entregando estrategias de enseñanza con el uso de tecnología, capacitando profesores, ofreciendo talleres para estudiantes y disponibilizando recursos educativos digitales e infraestructura. (ENLACES, 2016).
} 
considerassem o uso do computador em atividades de ensino e aprendizagem. Mais recentemente começaram a surgir propostas que dizem respeito ao próprio ensino da Ciência da Computação, no caso concreto do Chile, por meio do já citado programa ENLACES, essa prática acontece na forma de oficinas e módulos de temas específicos, como robótica e computação gráfica.

Essas oficinas, no entanto, têm um alcance limitado, pois cobrem anualmente cerca de $25 \%$ das escolas de Educação Básica, e entre elas, somente o grupo de estudantes interessados e durante o ano em que recebem apoio explícito do Ministério, razão pela qual necessariamente não chegam a se constituir uma oferta permanente para os alunos. (Tradução Nossa, Microsoft Latinoamérica, 2016, p. $18)^{10}$.

Consultando o Manual do Professor em Robótica Inicial, uma das oficinas ofertadas pelo programa ENLACES, em que se tem como público alvo alunos do 60 Ano do Ensino Fundamental, encontramos que um dos materiais proposto para as atividade é o kit de robótica Lego. Além de apresentar o passo a passo para a montagem das peças, dito manual também propõe o uso do software LEGO ${ }^{\circledR}$ Education $\mathrm{WeDo}^{\mathrm{TM}}$, no qual por meio de programação em blocos, os alunos podem dar movimentos às armações previamente montadas, atendendo a uma especificação apresentada na forma de exercício.

No caso do Chile, quanto a formação do profissional docente que irá desenvolver as práticas de ensino da Ciência da Computação, não encontramos um programa/proposta específico, ao menos nos documentos consultados. Existe a opção, dentro do próprio portal do referido programa ENLACES, uma plataforma que no âmbito da formação continuada de professores, permite ao profissional já atuante na atividade docente, realizar cursos de capacitação sobre algum conteúdo específico envolvendo a Ciência da Computação, na modalidade EaD.

Talvez, um dos fatores pouco favorável nessa escolha de capacitação de professores para ensinar Ciência da Computação, seja o contraponto sempre existente que haverá entre a formação original desse docente e a Ciência da Computação.

\section{Considerações Finais}

A partir da consulta a documentos e relatórios produzidos em língua espanhola, nos quais são abordados temas relativos à inserção da Ciência da Computação na Educação Básica, se percebeu a contemporaneidade e relevância desse assunto. Notou-se também, que em países vanguardistas nesse assunto como a Espanha, em que já existe a Ciência da Computação na grade curricular de ensino em várias escolas públicas e privadas, há deficiência no atendimento à demanda de professores qualificados. Nas leituras que foram realizadas até o presente momento, não encontramos nas universidades daquele país e nos demais aquí relacionados, a oferta de um curso equivalente ao de Licenciatura em Computação, sendo adotada em seu lugar, como medida paliativa, capacitação de professores já formados, no âmbito da formação continuada. Nesse

\footnotetext{
${ }^{10}$ Estos talleres, sin embargo, tienen un alcance limitado, pues cubren anualmente a cerca del $25 \%$ de las escuelas secundarias y dentro de estas, solo a grupos de estudiantes interesados y durante el año en que reciben apoyo explícito desde el Ministerio, por lo que no necesariamente alcanzan a constituir una oferta permanente para los estudiantes. (Microsoft Latinoamérica, 2016, p.18).
} 
sentido entendemos que no Brasil há relativa vantagem nesse aspecto, porém é preciso também fornecer ao licenciando em computação, para além de conhecimentos próprios de sua área de estudo, metodologias de ensino.

Faz-se necessário que as agremiações e instituições interessadas no ensino da Ciência da Computação na Educação Básica, desenvolvam materiais didáticos que além de contemplar a abordagem de temas correlatos à essa ciência de forma modular (oficinas), também pensem em conteúdos que sejam sistematicamente compatíveis com o programa de ensino formal, permitindo seu aprofundamento progressivo ao longo dos doze anos que compõem a Educação Básica em território nacional. Pensar em questões como: Qual a carga horária semanal para a Ciência da Computação no Ensino Fundamental II? E no Ensino Médio? Qual conteúdo deverá integrar a ementa em cada ano em específico? Em que nível de aprofundamento? Quais conceitos deverão ser abordados? A partir desses conceitos, quais habilidades e competências se espera que o aluno desenvolva? Pensando nesses aspectos próprios da Educação Básica, contextualizando-os ao ensino da Ciência da Computação, poderá permitir ao licenciado em Computação uma atuação mais significativa quando inserido no mercado de trabalho, desenvolvendo atividades para a qual sua formação lhe credencia: Ensinar Ciência da Computação na Educação Básica.

Acreditamos que o momento é propício para o aprofundamento dessa discussão, de maneira a permitir ao licenciado em computação, quando inserido no contexto educacional da Educação Básica, tenha ao seu dispor material literário e didático, que lhe permita o exercício pleno de suas funções.

\section{Referências}

Brasil, MEC. (1996) “Lei de Diretrizes e Base da Educação 9394/96”. Brasilia.

Fundación Omar Dengo e Ministerio De Educación Pública. (2016) "Estándares de desempeño de estudiantes en el aprendizaje con tecnologías digitales", http://www.fod.ac.cr/.

Gobierno De España, Google, Fundación Española Para La Ciencia y La Tecnología e Everis. (2016) "Educación en Ciencias de la Computación en España 2015", http://www.everis.com/spain/.

Lemos, A. S. (2013) "Entre Patinho Feio e Bela Adormecida: em busca do sentido de uma Licenciatura em Computação. Revista Espaço Acadêmico" in Revista Espaço Acadêmico $\mathrm{N}^{\circ}$ 148. Setembro.

Ministerio De Educación del Gobierno De Chile e Centro de Educación y Tecnología ENLACES. (2015) "Manual del Tutor: Taller de Robótica”, http://www.enlaces.cl/.

Olivette, C. (2016) "Cresce o número de escolas que ensinam linguagem de programação para crianças", in Jornal Estadão, http://economia.estadao.com.br/. São Paulo.

Plano Nacional De Educação. (2014) "Portal Observatório do PNE", http://www.observatoriodopne.org.br/.

Ramos, H. A. (2014) "Pensamento Computacional na Educação Básica: uma proposta de aplicação pedagógica para alunos do quinto ano do Ensino Fundamental do Distrito Federal" in Monografias da Universidade de Brasília.

Sociedade Brasileira De Computação. (2017) "Referenciais de Formação em Computação: Educação Básica”. http://www.sbc.org.br/. 
VI Congresso Brasileiro de Informática na Educação (CBIE 2017)

Anais dos Workshops do VI Congresso Brasileiro de Informática na Educação (WCBIE 2017)

Universidad Nacional Autónoma De México - UNAM. (2009) "Conocimientos Fundamentales de Computación", Dirección General de Publicaciones y Fomento Editorial, $1^{\text {a }}$ edición. México. 